\title{
Doctrine of Purchasing Power Parity: An Analysis based on Cointegration and Wavelet regression
}

\author{
Niyati Bhanja ${ }^{1}$ Arif Billah Dar ${ }^{2}$ Amaresh Samantaraya ${ }^{3}$ \\ 1,2,3 (Department of Economics, Pondicherry University, Puducherry-605014, India)
}

\begin{abstract}
The study revisits the doctrine of purchasing power parity (PPP) for four major bilateral exchange rates against Indian rupee namely; rupee-dollar, rupee-pound, rupee-yen and rupee-euro exchange rates. First, the long run validity of the hypothesis is tested using Granger-Engle cointegration along with Johansen multivariate cointegration technique. Both the tests provide support for the PPP hypothesis at the long run. Further, the issue is examined under time domain framework using recently advanced Wavelet-based regression analysis that provide decisive support for the PPP over 4 8 months horizon for rupee-dollar exchange rate and over 4 8 months as well as over more than 32 months horizon for the rupee-Yen exchange rate.
\end{abstract}

Keywords: Cointegration, Foreign exchange rate, Purchasing power parity, Wavelet.

\section{Introduction}

Understanding the behaviour of exchange rate is one of the highly exciting and debated issues within the area of international finance. Intense research activities have been carried out by researchers and academicians to trace the behaviors of exchange rate both under the perspective of short and long run. This study attempts to analyse the behaviour of exchange rate in the light of most prominent theory of exchange rate determination, namely, Purchasing Power Parity (PPP). The PPP is one of the cornerstones in the international macroeconomics and provides fundamental building block for many sophisticated exchange rate models. Based on the Law of One Price (LOP), the PPP hypothesis states that prices in the two different countries should be equal to each other when expressed in terms of the same currency. Constructed as a long-run theory of equilibrium exchange rate, PPP duly recognizes the possible deviations in the short-run from the parity. It, however, argues for forces capable of restoring the parity in the long-run. In its absolute version PPP requires the nominal exchange rate to be proportional with the ratio of the domestic to the foreign price level. This form of PPP is quite unlikely to hold precisely because the existence of transportation cost, distorting effects of tariff and non-tariff barriers to trade and imperfect information. Nonetheless, it is argued that a weaker form of PPP known as relative PPP can be expected to hold even in the presence of such distortion. This weaker form of PPP argues that exchange rate will adjust by the amount of inflation differential between two economies.

There are various considerations from policy perspective that makes empirical validity of the PPP doctrine highly crucial. First, rejection of PPP in some sense indicates persistent misalignment of exchange rate (Alba and Park, 2005). Second, for determining parities of exchange rate PPP concept is often put into practice. Third, it is also used to estimate exchange rate misalignment i.e. deviation of exchange rate from equilibrium level, and in devising proper policy response. Last but not the least, the hypothesis of PPP provides the fundamental assumption of many exchange rate models that has developed in later stage e.g. flexible-price monetary model, over-shooting model of Dornbusch (1976). It is, thus, imperative to examine the validity of PPP hypothesis empirically.

There has been extensive research activity carried out over the years evaluating empirical validity of the PPP doctrine. No conclusive evidence yet, however, reached at. The support for PPP has waxed and waned over the years. Working with very long panel data set; covering say a particular era or monetary regime, studies of Officer (1982), Abauf and Jorion (1990), Lothian (1990), Lothian and Taylor (1996) amongst others uncovered strong evidence of mean reversion in real exchange rate validating PPP hypothesis. On the other side, the empirical studies based on time series analysis of short spans of data for recent floating-rates (e.g. Frenkel; 1981, Meese and Rogoff; 1983) led to mass rejection of PPP hypothesis. These studies, nevertheless, have been criticized for their low power of tests and insufficient time-series variation. The research activity over last two decades, however, has witnessed a renewed interest in PPP that exploits more data and sophisticated higherpowered techniques and non-linear methods to overcome shortcomings of earlier studies. This generation of research [Cheung and Lai 1998, Taylor and Sarno 1998, Culver and Papell 1999, Bahmani-Oskooee and Gelan 2006; Wallace 2008; Chang et al., 2010] have demonstrated validity of PPP with rejection of the so-called random walk hypothesis and mean reversion of real exchange rate. With these newly emerging literatures, now it appears that in the long run PPP indeed holds with a half-life of deviations being 3 to 5 years (Taylor 1995; Froot and Rogoff, 1995, Taylor and Taylor, 2004). 
Moreover, the plethora of empirical literature on the Purchasing Power Parity seems highly lop-sided given the disproportionately thin number of studies available in the context of developing economies. One of the earliest studies of PPP on developing economies is conducted by McNown and Wallace (1989); that tested for cointegration using both monthly CPI and WPI data for four high inflation countries of Argentina, Brazil, Chile, and Israel. Using Engle-Granger two-step method, they found supportive evidence of PPP in Argentina, Chile, and Israel. More recently, a study by Doganlar et al. (2009) examined the PPP hypothesis for ten emerging market economies including India. Employing Johansen cointegration technique, the study rejected co-integration between the exchange rate and prices for eight countries including India.

Studies in Indian context are relatively handful. Among others, Kulkarni and Chakraborthy (1990) using Ordinary Least Squares have found evidence supporting relative PPP for INR-USD exchange rate over the period 1977 through 1987. Under cointegration framework Moshin and Kamaiah (1993), however, report no long-run relationship between exchange rate of INR vis-à-vis USD, Pound, German Mark and Japanese Yen, and the corresponding price ratios; thus, rejecting long run validity of PPP. In another rigorous study Nag and Mitra (1998) reported mixed result for Rupee-Dollar exchange rate for the period 1957 to June 1997. Working with Engle-Granger two-step co-integrating regression framework, they found some evidence of cointegration at only 10 percent level of significance; however the coefficient restrictions imposed by absolute and relative PPP were rejected by Wald's test. Further, Johansen's cointegration test under VAR set-up though showed existence of at least one co- integrating vector, the error correction coefficients turns out not to be significant. The study, thus, concludes that in the long run there is unmistakable evidence for some degree of impact of changes in price-ratios on the nominal exchange rate, though strength of this relation is not as rigid and strong as predicted by PPP. Employing higher-powered unit-root tests e.g. ADF-GLS and ADF-WS; that promise to improve power of small sample, Kohli (2002) showed that both CPI-deflated as well WPI-CPI ratio deflated real rupee-dollar exchange rate to exhibit mean-reverting tendencies over floating regime (1993:01 to 2001:03) of India. However, the data set did not support mean-reversion or stationarity of trade-weighted REER series over the same period.

On the above backdrop, it may be noted that exchange rate of Indian Rupee vis-à-vis US dollar has witnessed significant swings in the recent years, particularly in the run up to and aftermath of recent global financial crisis. The purpose of the present study is two-fold. Firstly, with latest data, it attempts to reexamine relative version of PPP for Indian Rupee against the currency of its leading trade partners USA, Japan, Great Britain and European Union using various econometric methodologies viz; Granger-Engle 2-step regression, Johansen multivariate cointegration procedure and finally recently developed methodology of semi-parametric wavelet based regression. Secondly, the major innovation of this paper lies with application of wavelet based regression technique that enables to decompose the variable of exchange rate change and inflation differential into different time scales and then to tests the validity of PPP at different time scales using Ordinary Least Squares (OLS).

This paper is organized as follows. Section II sets out the methodology used in this study. Section III provides details of data used for estimation. Section IV reports the results with inferences and the final section $\mathrm{V}$ concludes.

\section{Methodology}

The present study use two different methods of cointegration test are used to reexamine the long run equilibrium relationship between nominal exchange rate, domestic and foreign price series; viz. Granger-Engle 2-step cointegration regression (1987) and Johansen-Juselius multivariate cointegration technique (1990). The Granger-Engle cointegration (1987) involves two-step estimation process: regression analysis based on the Ordinary Least Squares (OLS) method followed by stationarity test of the regression residual. This approach, however, fails to detect the number of cointegration vectors in case of more than two variables and suffers from simultaneous equation bias. The cointegration technique of Johansen and Juselius (1990) nevertheless, addresses these issues employing system of VAR to detect number of cointegrating vectors and the Maximum Likelihood (ML) methodology for the estimation. Both of these tests have been popularized by many applications and are considered as standard procedures for testing cointegration. Detail discussion of these methodologies discussion is hence avoided. ${ }^{1}$ The equation estimated for Bivariate Granger-Engle cointegrating regression:

$$
\ln E_{t}=\beta_{0}+\beta_{1}\left(\ln P_{t}-\ln P_{t}^{*}\right)+u_{t}
$$

and for the Johansen multivariate cointegration method we consider the following vector in VAR framework:

$$
\ln \left(E_{t}\right) \ln \left(P_{t}\right) \ln \left(P_{t}^{*}\right)
$$

\footnotetext{
${ }^{1}$ For further reference see Granger-Engle (1987), Johansen and Juselius (1990), and Johansen (1991). 
where, $\ln E_{t}$ is the $\log$ of the domestic exchange rate per unit of foreign currency, $\ln P_{t}$ is the log of domestic price index and $\ln P_{t}^{*}$ is the $\log$ of foreign price index and $\boldsymbol{u}_{t}$ is stochastic disturbance term.

We also use the wavelet methodology to decompose the exchange rate change and inflation differentials into different time scales. Wavelets are mathematical functions that give the mathematically equivalent representation of data and cut up data into different frequency components, with a resolution matched to its scale. These functions use basis function that is dilated (through a scale or dilation factor) and shifted (through a translation or location parameter) along the signal so as to provide a time-frequency representation where all information is associated with specific time horizons and locations in time. Wavelet are similar to a sine and cosine functions because they oscillate around zero, but differ because they are well localized both in the time and frequency domains. In contrast to Fourier analysis, wavelets are compactly supported as all projections of a signal onto the wavelet space are essentially local, not global, and thus need not be homogeneous over time. Wavelets are flexible in handling a variety of non-stationary signals. Wavelets, in opposition to time and frequency domain analysis, consider non-stationarity as an intrinsic property of the data rather than a problem to be solved by pre-processing the data.

There are two basic wavelet functions: the father wavelet and the mother wavelet. Formally the father wavelets can be represented as

$$
\Phi_{j, k}=2^{-j / 2} \Phi\left(\frac{t-2^{j} k}{2^{j}}\right)
$$

Defined as non-zero over a finite time length support that corresponds to mother wavelets given by

$$
\psi_{j . k}=2^{-j / 2} \psi\left(\frac{t-2^{j} k}{2^{j}}\right)
$$

where $\mathrm{J}=1,2,3, \ldots, \mathrm{J}$ in a $\mathrm{J}$-level decomposition. The father wavelet integrates to one and reconstructs the trend component (longest time scale component) of the series. The mother wavelet integrates to zero and describes all deviations from the trend. In order to compute the decomposition, wavelet coefficients at all scales representing the projections of the time series onto the basis generated by the chosen family of wavelets need to be calculated first, they are

$$
\begin{aligned}
d_{j, k} & =\int f(t) \psi_{j, k} \\
s_{j, k} & =\int f(t) \Phi_{j, k}
\end{aligned}
$$

Coefficients $d_{j . k}$ and $S_{j, k}$ are wavelet transform coefficients representing the projection onto mother and father wavelets, respectively.

The series or function $f(t)$ in $L^{2}(R)$ can be shown in wavelet representation as

$$
f(t)=\sum_{k} S_{j, k} \Phi_{j, k}(t)+\sum_{k} d_{j, k} \psi_{j, k}(t)+\cdots+\sum_{k} d_{j-1, k} \psi_{j, k}(t)+\cdots+\sum_{k} d_{1, k} \psi_{1, k}(t) \ldots \cdots
$$

Here $\boldsymbol{J}$ refers to the number of scales (multiresolution components) and $K$ ranges from 1 to the number of coefficients in the specified components. The original time series $f_{t}$ in multiresolution decomposition framework can be given as

$$
\begin{aligned}
& f(t)=S_{j}+D_{j}+D_{j-1}+\cdots D_{j}+\cdots+D_{1} \\
& S_{j}, D_{j} \text { represent } \sum_{k} S_{j, k} \Phi_{j, k}(t) \text { and } \sum_{k} d_{j, k} \psi_{j, k}(t) \text { respectively with } j=1, \cdots, J .
\end{aligned}
$$

The sequential set of terms $\left(S_{j}, D_{j}, \ldots D_{j}, \ldots, D_{1}\right)$ in equation (6) show the components of original unfiltered series represented at different resolutions. These components at different resolutions are therefore, again estimated using Equation (1). differential;

Finally, we test the equation for relationship between unfiltered exchange rate change and inflation

$$
\Delta \ln E_{t}=\beta_{0}+\beta_{1}\left(\Delta \ln P_{t}-\Delta \ln P_{t}^{*}\right)+u_{t}
$$

Where, $\Delta$ the one-period change in the variable and other variables are as explained earlier. All series are expressed in natural logarithms form and the change in the log of a variable represents relative change in the variable. For PPP to hold the regression estimates suppose to yield $\beta_{1}=1$. 


\section{DATA}

The data used in this study are monthly observation spanning from April 1992 to September 2010. Most part of the sample period corresponds to market-based exchange rate system in India emerged on March 1993. Nominal exchange rates are the bilateral exchange rate of Indian Rupee vis-a-vis US dollar, British Pound, Japanese Yen and European Union's Euro. The data are taken from the Handbook of Statistics on Indian Economy 2011-12 published by the Reserve Bank of India. Exchange rates in terms of above four foreign currencies guided by the fact that they are major currencies traded in the international market and these countries are leading trade partners for India. Wholesale price Index (WPI) of India and Consumer Price Index (CPI) of its trade partners are used to represent domestic and foreign price respectively and the data source is the International Financial Statistics (IFS) CD-ROM 2012 published by the International Monetary Fund (IMF). In Indian case we used WPI as the indicator for general prices due to its advantage in terms of coverage, updated base and wide use in policy and research.

\section{Results And Discussion}

This section sets out the approach for testing the PPP hypothesis. To ensure the validity of the different econometric tests, first the stationary property of all the time series are tested by using Augmented DickeyFuller (ADF) and Phillips-Perron (PP) tests. The appropriate lag structures were selected by Schwartz Information Criterion (SIC) for ADF and Newey West using Bartlett Kernel for PP tests. The unit root results are presented in Table 1. All the statistics show that nominal exchange rate and price series are non-stationary at their levels but stationary at first difference.

\section{Table.1}

Unit Root Test Results

\begin{tabular}{llllll}
\hline & & \multicolumn{2}{c}{ ADF Value } & \multicolumn{2}{c}{ Phillip-Perron Value } \\
\cline { 3 - 6 } Country & Series & Level & First difference & Level & First difference \\
\hline \multirow{2}{*}{ India } & WPI & $-0.99(0.75)$ & $-11.18(0.00)$ & $-1.08(0.72)$ & $-11.15(0.00)$ \\
\multirow{2}{*}{ USA } & CPI & $-0.87(0.79)$ & $-9.70(0.00)$ & $-0.83(0.80)$ & $-8.09(0.00)$ \\
& EXR & $1.27(0.94)$ & $-12.16(0.00)$ & $-1.90(0.33)$ & $-12.18(0.00)$ \\
\multirow{2}{*}{ UK } & CPI & $1.22(0.99)$ & $-2.87(0.05)$ & & \\
& EXR & $-1.39(0.58)$ & $-11.92(0.00)$ & $-1.45(0.55)$ & $-11.69(0.00)$ \\
\multirow{2}{*}{ JAP } & CPI & $-2.34(0.15)$ & $-3.09(0.03)$ & $-2.69(0.08)$ & $-13.16(0.00)$ \\
& EXR & $-1.72(0.41)$ & $-12.01(0.00)$ & $-1.63(0.47)$ & $-12.16(0.00)$ \\
\multirow{2}{*}{ EU } & CPI & $-2.34(0.41)$ & $-5.25(0.00)$ & $-2.13(0.52)$ & $-11.55(0.00)$ \\
& EXR & $-1.28(0.64)$ & $-14.61(0.00)$ & $-1.28(0.64)$ & $-14.61(0.00)$ \\
\hline
\end{tabular}

Figures in (\#) are p-values and the values higher than $0.05(5 \%)$ show that unit root hypothesis is not rejected.

We proceed to test the PPP hypothesis using various cointegration methodologies. Starting with simple Granger- Engle (1978) two-step procedure, the OLS regression based on equation (1) is first carried out and subsequently residuals are tested for stationarity using ADF, Phillps-Perron and KPSS procedure. If the variables are cointegrated the residual should follow stationary process. The results so obtained are reported in Table 2. It may be observed that, the null of non-stationarity is rejected for Japan and European Union under the test of ADF and Philip-Perron, indicating existence of long run association between the nominal exchange rate and the corresponding price variables.

However, the traditional unit root tests are not very powerful against relevant alternatives (Diebold and Rudebusch, 1991). The traditional unit root tests by design are formulated to ensure the acceptance of null hypothesis of unit-root unless there is strong evidence against it (Chen, 1995). We thus directly test the null of no-unit root for residuals from OLS regression using KPSS test. The KPSS test results presented in Table 2 show that, apart from EU the null of stationarity of error term cannot be rejected for any of the country under consideration. Moreover, the Wald test statistics accepts the proportionality restriction $\left(\beta_{1}=1\right)$ for both USA and UK. Therefore we argue that there is some evidence in favour of long run PPP though the support is weak. 
Table.2

Granger-Engle 2-step Cointegration test results:

\begin{tabular}{|l|l|l|l|l|}
\hline & ADF Test & Phillip-Perron & KPSS & $H_{0}: \beta_{1}=1$ \\
\hline USA & -1.24 & -1.37 & 0.37 & $\begin{array}{l}2.45 \\
(0.12)\end{array}$ \\
\hline UK & -1.42 & -1.67 & 0.27 & $\begin{array}{l}1.92 \\
(0.17)\end{array}$ \\
\hline JAPAN & $-2.81^{*}$ & $-2.61^{*}$ & 0.12 & $\begin{array}{l}67.04^{*} \\
(0.00)\end{array}$ \\
\hline EU & $-1.98^{* *}$ & $-2.01^{* *}$ & $0.57 * *$ & $\begin{array}{l}1732.95 * \\
(0.00)\end{array}$ \\
\hline
\end{tabular}

Note: Figures in (\#) are p-values and the values higher than 0.05 (5\%) show that unit root hypothesis is not rejected. For KPSS test critical values are 0.739, 0.463, 0.347corresponding to $1 \%, 5 \%$ and $10 \%$ level of significance respectively. $*$ and $* *$ denote significance at $1 \%$ and $5 \%$ level, respectively.

To gain further insight into the issue, the long run equilibrium relation between nominal exchange rate and two price series are tested using Johansen multivariate cointegration technique (Johansen, 1988, 1991). First the weak-version of PPP that imposes no restriction on the cointegrating vector and requires only the cointegration among the exchange rate and the two price series, is tested. Second, the test for the strong-version of PPP that implies not only the existence of at least one cointegrating vector but also that the proportionality restrictions are satisfied, is conducted.

Before starting the cointegration analysis, the appropriate lag length $k$ in VAR is determined using Schwartz Information Criterion (SIC) for specifying the lag structures of the equations in the VARs. The Johansen cointegration test then has been conducted and the results are reported in Table 3 . The cointegration results show that for both the trace and maximum eigenvalue tests the hypothesis of no cointegrating vector is rejected for Rupee exchange rate vis-à-vis USD, Pound Sterling and Euro at 1 percent level of significance. In case of Japan, however, two cointegrating vector is detected by the trace test at 5 percent significance level, but the maximum-eigen result suggest only one cointegrating vector at 1 percent level.

Table.3

Johansen cointegration test results

\begin{tabular}{|c|c|c|c|c|}
\hline Country & Lag & Hypothesized no. of $\mathrm{CE}(\mathrm{s})$ & Trace statistic & Max-Eigen \\
\hline \multirow{3}{*}{ USA } & \multirow{3}{*}{2} & None* & $52.99(0.00)$ & $44.28(0.00)$ \\
\hline & & At most 1 & $8.71(0.76)$ & $5.65(0.83)$ \\
\hline & & At most 2 & $3.06(0.57)$ & $3.06(0.57)$ \\
\hline \multirow{3}{*}{ UK } & \multirow{3}{*}{2} & None* & $48.70(0.00)$ & $31.26(0.00)$ \\
\hline & & At most 1 & $17.44(0.12)$ & $14.38(0.08)$ \\
\hline & & At most 2 & $3.06(0.57)$ & $3.06(0.57)$ \\
\hline \multirow{3}{*}{ JAPAN } & \multirow{3}{*}{1} & None* & $70.86(0.00)$ & $50.03(0.00)$ \\
\hline & & At most $1 * *$ & $20.83(0.04)$ & $12.20(0.17)$ \\
\hline & & At most 2 & $08.63(0.06)$ & $08.63(0.06)$ \\
\hline \multirow{3}{*}{$\mathbf{E U}$} & \multirow{3}{*}{1} & None* & $83.11(0.00)$ & $64.01(0.00)$ \\
\hline & & At most 1 & $19.20(0.07)$ & $11.71(0.20)$ \\
\hline & & At most 2 & $0.03 \quad(0.16)$ & $7.38 \quad(0.11)$ \\
\hline
\end{tabular}

Figures in (\#) are p-values. **and * denotes rejection of the hypothesis at $5 \%$ and $1 \%$ level respectively.

Table 4 reports estimates of the cointegrating vector normalized on the spot exchange rate. ${ }^{2}$ These estimates have coefficients carrying correct signs only in case of Japan and EU, however, are statistically insignificant. The formal test results for the symmetry $\left(\beta_{1}=\beta_{2}\right)$ and proportionality $\left(\beta_{1}=\beta_{2}=1\right)$ restrictions are also

\footnotetext{
${ }^{2}$ When there is more than one cointegration vector, we have chosen the one corresponding to the largest
} eigenvalue. following Chen (1995). 
reported Table 4. The Likelihood ratio (LR) test suggested by Johansen and Juselius (1990) provide strong evidence in favour of both symmetry and proportionality hypothesis for all the countries under the study. The Johansen's maximum likelihood approach, hence, suggest cointegration among nominal exchange rate and two price series validating long run PPP hypothesis.

We then proceed to estimate the error correction model (ECM) to analyse how short run discrepancy, if any, corrected thus, to capture how rapidly long-run PPP is attained. The estimate of the matrix of the error correction terms are presented in Table 5. The coefficients of this matrix are interpreted as the weights with which PPP deviation is corrected in each of the three equations (Kouretas, 1997). The error correction terms from the equation for the change in the exchange rate and foreign price have correct sign only for USA and EU. However, adjustment coefficient from the change in the domestic price equation carries wrong sign in each of the cases except for Japan. The magnitudes of adjustment coefficients in all the cases, moreover, are very poor and almost close to zero. The Johansen multivariate cointegration test, thus, suggest evidence in favour of both weak and strong version of long run PPP, though convergence speed of deviation from PPP is reasonably low at around zero level.

Table.4

Estimated Coefficients and Hypothesis testing

\begin{tabular}{|c|c|c|c|c|}
\hline \multicolumn{5}{|c|}{$e_{t}=\beta_{0}+\beta_{1} p_{t}-\beta_{2} p_{t}^{*}+u_{t}$} \\
\hline & \multicolumn{2}{|c|}{ Eigen Vectors } & \multicolumn{2}{|c|}{ Hypothesis Test } \\
\hline & $\beta_{1}$ & $\beta_{2}$ & {$\left[H_{1}: \beta_{2}=\beta_{3}\right]$} & {$\left[H_{2}: \beta_{2}=\beta_{3}=1\right]$} \\
\hline USA & $\begin{array}{c}1.69 \\
(0.66)\end{array}$ & $\begin{array}{c}-3.62 \\
(-0.68)\end{array}$ & $\begin{array}{c}0.35 \\
{[0.55]}\end{array}$ & $\begin{array}{c}0.42 \\
{[0.52]}\end{array}$ \\
\hline UK & $\begin{array}{c}3.00 \\
(0.74)\end{array}$ & $\begin{array}{l}-10.39 \\
(-0.86)\end{array}$ & $\begin{array}{c}0.29 \\
{[0.59]}\end{array}$ & $\begin{array}{c}0.45 \\
{[0.50]}\end{array}$ \\
\hline JAPAN & $\begin{array}{c}-1.33 \\
(-1.51)\end{array}$ & $\begin{array}{c}38.09 \\
(-1.79)\end{array}$ & $\begin{array}{c}2.46 \\
{[0.12]}\end{array}$ & $\begin{array}{c}2.72 \\
{[0.49]}\end{array}$ \\
\hline EU & $\begin{array}{l}-1.78 \\
(-1.16)\end{array}$ & $\begin{array}{c}0.59 \\
(2.03)\end{array}$ & $\begin{array}{c}1.29 \\
{[0.26]}\end{array}$ & $\begin{array}{c}0.46 \\
{[0.49]}\end{array}$ \\
\hline
\end{tabular}

Notes: $e_{t}, p_{t}$ and $p_{t}^{*}$ denotes the spot exchange rate, domestic and foreign price index respectively. The eigenvectors have been normalized with respect to the estimated coefficient on the nominal exchange rate $e_{t} \cdot H_{1}$ and $H_{2}$ denotes a likelihood statistic for the null hypothesis indicated in parenthesis, constructed as central $\chi^{2}$ under the null with $r \times s$ degrees of freedom, where $r$ denotes the number of cointegrating vectors and $s$ is the number of restrictions. (\#) are t-statistics and [\#] are marginal significance levels.

Table.5

Speed of Adjustment Mechanism

\begin{tabular}{|c|ccc|}
\hline & $\boldsymbol{e}_{\boldsymbol{t}}$ & $\boldsymbol{p}_{\boldsymbol{t}}$ & $\boldsymbol{p}_{\boldsymbol{t}}{ }^{*}$ \\
\hline \multirow{2}{*}{ USA } & -0.002 & -0.004 & -0.002 \\
& $(-1.07)$ & $(-4.99)$ & $(-5.84)$ \\
UK & 0.001 & -0.003 & -0.001 \\
& $(0.25)$ & $(-4.92)$ & $(-3.43)$ \\
JAPAN & 0.000 & 0.002 & 0.000 \\
& $(0.79)$ & $(7.29)$ & $(0.45)$ \\
EU & -0.005 & -0.002 & -0.013 \\
& $(-2.09)$ & $(-5.73)$ & $(-6.48)$ \\
\hline
\end{tabular}

Notes: (\#) are t-statistics.

The major limitation, however, with cointegration and error correction methodology is that it fails to point out the exact time period within which PPP holds. This study addresses this crucial issue with recently advanced semi-parametric wavelet based regression methodology. Under this framework our study attempts to address following controversial issues surrounding the PPP theory: First; is PPP a valid theory pertaining to different time scales (long run, medium run and short run) or exclusive to long run as evident from our empirical exercise conducted above? Second; what exactly is the time scale within which PPP holds if it is a valid hypothesis? 
We first examine the stationary property of the nominal exchange rate change and inflation differential by using Augmented Dickey-Fuller and Phillips-Perron tests. The results are presented in Table 6 and it shows that all series are stationary at levels. We use the Daubechies (LA8) least asymmetric to decompose both the series into different time scales. Further Maximal Overlap Discrete Wavelet Transform (MODWT) was used over the more conventional orthogonal DWT because, by giving up orthogonality, the MODWT gains attributes that are far more desirable in economic applications. For example, the MODWT can handle input data of any length, not just powers of two; it is translation invariant - that is, a shift in the time series results in an equivalent shift in the transform; it also has increased resolution at lower scales since it oversamples data (meaning that more information is captured at each scale); the choice of a particular wavelet filter is not so crucial if MODWT is used and, finally, excepting the last few coefficients, the MODWT is not affected by the arrival of new information. The application of the MODWT with a number of scales $\mathrm{J}=4$ produces five MODWT detail vectors $\mathrm{D}_{1}, \mathrm{D}_{2}, \mathrm{D}_{3}, \mathrm{D}_{4}$ and one smooth vector $\mathrm{A}_{4}$, where each

Table.6

Unit root test

\begin{tabular}{llllll}
\hline $\boldsymbol{E X R}$ change & $\boldsymbol{A D F}$ & $\boldsymbol{P P}$ & Inflation Diff. & $\boldsymbol{A D F}$ & $\boldsymbol{P P}$ \\
\hline Rupee-Dollar & $-12.16^{*}$ & $-12.18^{*}$ & India-US & $-11.94^{*}$ & $-11.97^{*}$ \\
Rupee-Pound & $-3.84^{*}$ & $-4.68^{*}$ & India-UK & $-6.94^{*}$ & $-14.27^{*}$ \\
Rupee-Yen & $-12.09^{*}$ & $-12.15^{*}$ & India- Japan & $-12.49^{*}$ & $-12.48^{*}$ \\
Rupee-Euro & $-24.13^{*}$ & $-1.40^{*}$ & India-Euro & $-6.99^{*}$ & $-11.36^{*}$ \\
\hline
\end{tabular}

Note: * denotes the significance at $1 \%$ level.

wavelet scale is associated with a particular time period $\left[2^{J}-2^{J+1}\right]$. Since we use monthly data, therefore the first detail level $\mathrm{D}_{1}$ capture oscillations between two to four months; while details $\mathrm{D}_{2}, \mathrm{D}_{3}, \mathrm{D}_{4}$ and $\mathrm{A}_{4}$ capture oscillations with periods between four-eight, eight-sixteen, sixteen-thirty two and more than thirty two months respectively. The time interpretations of different scales are presented in appendix Table.1. We run the regressions for aggregate time series and series at different time scales by estimating equation (7). At aggregate level (Agg) and lower scale D1 there is no evidence of the parity to hold. However, our ordinary least square results stemming from the regressions at time scale $\mathrm{D}_{2}$ exhibit some evidence for validity of PPP for rupeedollar and rupee-yen rate. Corresponding to time scale $\mathrm{D}_{2}$, that captures variation over four-eight months period, the coefficient of inflation rate differential $\left(\beta_{1}\right)$ in case of India-US and India-Japan regression found to be significant at $5 \%$ level. The Wald restriction of $\beta_{1}=1$ is also accepted for the regression corresponding to India-Japan at $\mathrm{D}_{2}$ time scale. The coefficient of inflation rate differential $\left(\beta_{1}\right)$ also found to be significant at scale $\mathrm{A}_{4}$, that captures oscillation over thirty two-sixty four months, for India-Japan regression at $5 \%$ level of significance with acceptance of restriction $\beta_{1}=1$ by the Wald test. The adjusted $\mathrm{R}^{2}$ nevertheless remains relatively low around 2 percent to 5 percent for both the regressions. No evidence of the parity, however, is obtained for UK and EU at any of the time scale.

Thus, for India, our results reject the validity of PPP at aggregate and very lower time scales (D1) but lend support only at medium to higher time scales; more specifically over 4 to 8 months horizon for rupee-dollar rate and over 4 to 8 months as well as over more than 32 months horizon for rupee-yen exchange rate.

Table.7

Regression results of exchange rate change on inflation differentials

\begin{tabular}{|c|c|c|c|c|c|c|}
\hline \multicolumn{7}{|l|}{ IND-US } \\
\hline & Agg & D1 & D2 & D3 & D4 & A4 \\
\hline$\beta_{0}$ & $0.00(0.25)$ & $0.00(0.99)$ & $-0.00(0.99)$ & $0.00(0.99)$ & $-0.0(0.99)$ & $0.00(0.00)$ \\
\hline$\beta_{1}$ & $0.21(0.19)$ & $0.11(0.67)$ & $0.44(0.05)$ & $0.10(0.62)$ & $0.64(0.13)$ & $-0.26(0.32)$ \\
\hline $\operatorname{Adj} R^{2}$ & 0.00 & -0.00 & 0.02 & -0.00 & 0.05 & 0.00 \\
\hline \multicolumn{7}{|l|}{ IND-UK } \\
\hline & Agg & D1 & D2 & D3 & D4 & A4 \\
\hline$\beta_{0}$ & $-0.0(0.74)$ & $0.00(0.42)$ & $0.00(0.99)$ & $0.00(0.99)$ & $-0.0(0.99)$ & $0.00(0.06)$ \\
\hline$\beta_{1}$ & $0.09(0.09)$ & $-0.14(0.65)$ & $0.09(0.76)$ & $0.03(0.91)$ & $0.99(0.18)$ & $-0.44(0.28)$ \\
\hline$A d j R^{2}$ & 0.00 & -0.00 & -0.00 & -0.00 & 0.03 & 0.01 \\
\hline \multicolumn{7}{|l|}{ IND- JP } \\
\hline & Agg & D1 & D2 & D3 & D4 & A4 \\
\hline
\end{tabular}


Doctrine of Purchasing Power Parity: An Analysis based on Cointegration and Wavelet regression

\begin{tabular}{|c|c|c|c|c|c|c|}
\hline$\beta_{0}$ & $0.00(0.30)$ & $0.00(0.99)$ & $0.00(0.99)$ & $0.00(0.99)$ & $-0.0(0.99)$ & $-0.00(0.79)$ \\
\hline$\beta_{1}$ & $0.16(0.61)$ & $-0.03(0.93)$ & $0.63(0.04)^{*}$ & $-0.24(0.65)$ & $-0.18(0.7)$ & $1.17(0.04)^{*}$ \\
\hline $\operatorname{Adj} R^{2}$ & -0.00 & -0.00 & 0.02 & -0.00 & -0.00 & 0.05 \\
\hline \multicolumn{7}{|l|}{ IND-EU } \\
\hline & Agg & D1 & D2 & D3 & D4 & A4 \\
\hline$\beta_{0}$ & $-0.01(0.0)$ & $0.00(0.99)$ & $-0.00(0.99)$ & $-0.00(0.99)$ & $0.00(1.00)$ & $0.00(0.38)$ \\
\hline$\beta_{1}$ & $-0.65(0.0)$ & $-1.57(0.00)$ & $-0.65(0.00)$ & $-0.16(0.0)$ & $-0.07(0.22)$ & $0.00(0.91)$ \\
\hline $\operatorname{Adj} R^{2}$ & 0.32 & 0.78 & 0.32 & 0.07 & 0.04 & -0.00 \\
\hline
\end{tabular}

Note: $p$-values are in parenthesis. Wald statistic is used to test the hypothesis of relative PPP $\quad\left(\beta_{1}=1\right)$. Coefficients statistically equal to one are shown in asterisk. Standard errors are corrected by Newey and West (1987) method.

The study, therefore, validates the Purchasing Power Parity as a theory basically pertains to medium to long time horizon; more precisely not at least to short run, corroborating our results of cointegration analysis. Moreover, in the light of consensus in the literature regarding the horizon over which PPP holds in the long run (about 7 to 10 years with a half-life deviation of 3 to 5 years), this study provides quite an encouraging timeframe for the long-run with PPP holding over 6 months to more than 32 months period.

\section{Conclusion}

This paper revisited the doctrine of Purchasing power parity considering four major bilateral exchange rates via-a-vis Indian-Rupee. The study first examined the long run validity of PPP hypothesis using two distinct cointegration techniques; the Granger-Engle cointegration and the Johansen-Juselius cointegration technique. The Granger-Engle test suggests validity of long run PPP, though weak, for all the exchange rates under the consideration. Corroborative results are also obtained with Johansen multivariate analysis. No significant error correction is, however, witnessed for any of the exchange rate under study. We move forward to analysis the hypothesis at different time domain using much advanced methodology of wavelet-based regression. The application of wavelet analysis provides a new look into PPP doctrine and an alternative reassessment of its validity over well-defined horizons rather than arbitrary-chosen short run or long run. The empirical results stem from the wavelet framework provide decisive support for PPP only at medium to higher time scales; more specifically in case of rupee-dollar exchange rate over four to eight months horizon and for the rupee-Yen exchange rate over four to eight months as well as over more than thirty two months horizon. Thus, we conclude that the PPP is a relevant hypothesis pertaining over medium to long-run only.

\section{References:}

[1] J.D. Alba, and D. Park, An empirical investigation of Purchasing Power Parity (PPP) for Turkey, Journal of Policy Modeling, 27, 2005, 989-1000.

[2] R. Dornbusch, Expectations and Exchange rate dynamics, Journal of Political Economy, 84(6), Dec. 1976, 1161-1176.

[3] L.H. Officer, Purchasing Power Parity and Exchange Rates: Theory, Evidence and Relevance, 1982, (Greenwich, CT: JAI Press)

[4] N. Abauf, and P. Jorion, Purchasing Power Parity in the long Run, Journal of Finance, 45(1), 1990, 157-174.

[5] J.R. Lothian, A Century of Yen Exchange Rate Behaviour, Japan and the World Economy, 2(1), 1990, 47-70.

[6] J. R. Lothian, and M. P. Taylor, Real Exchange Rate Behaviour: The Recent Float from the Perspective of the Past Two Centuries, Journal of Political Economy, 104(3), 1996, 488-509.

[7] J.A. Frenkel, Flexible Exchange Rates, Prices, and the Role of "News": Lessons from the 1970s, Journal of Political Economy, 89(4), Aug. 1981, 665-705.

[8] R. Meese, and K. Rogoff, The Out-of-Sample Failure of Empirical Exchange Rate Models: Sampling Error or Misspecification?, Exchange Rates and International Macroeconomics, 1983, 67-112, National Bureau of Economic Research, Inc.

[9] Y. W. Cheung, and K. S. Lai, Parity reversion in real exchange rate during the post-Bretton Woods period, Journal of International Money and Finance, 17(4), 1998, 597-614.

[10] M.P. Taylor, and L. Sarno, The Behaviour of Real Exchange Rates during the post-Bretton Woods Period, Journal of International Economics, 46, 1998, 281-312.

[11] S. E. Culver, and D.H. Papell, Long Run PPP with Short-Run Data: Evidence with a Null Hypothesis of Stationarity, Journal of International Money and Finance, 18(5), 1999, 751-768.

[12] M. Bahamani-Oskooee, and A. Gelan, Testing the PPP in the non-linear framework: Evidence from Africa, Economics Bulletin, 6 , 2006, 1-15.

[13] F. Wallace, Nonlinear unit root tests of PPP using long-horizon data, Economics Bulletin, 6, 2008, 1-8.

[14] T. Chang, S.Y. Lin, and H.J. Chang, Are real exchange rates nonlinear with a unit root? Evidence on purchasing power parity for China: A note, Economics Bulletin, 30, 2010, 1897-1905

[15] M.P. Taylor, The Economics of Exchange Rates, Journal of Economic Literature, 33(1), 1995, $13-47$.

[16] K. A. Froot, and K. Rogoff, Perspectives on PPP and Long-run Real Exchange Rates, Handbook of International Economics, 3(1), $1995,1647-1688$

[17] A.M. Taylor, and M.P. Taylor, The purchasing power parity debate, Journal of Economic Perspectives, 18, 2004, 135-58.

[18] R. McNown, and M.S. Wallace, National Price Levels, Purchasing Power Parity, and Cointegration: A Test of Four High Inflation Economies, Journal of International Money and Finance, 8(4), 1989, 533-546. 
[19] M. Dogganlar, H. Bal, and M. Ozmen, Testing long-run validity of purchasing power parity for selected emerging market economies, Applied Economics Letters, 64(14), 2011, 1443-1448.

[20] K. Kulkarnni, and D. Chakraborthy, An Empirical Evidence of PPP Theory: A Case study of Indian Rupee and US dollar, Margin, 22(1) \& (2), 1990, 52-56.

[21] Md. Moshin, and B. Kamaiah, PPP Doctrine: An Empirical Verification, Journal of Foreign Exchange and International Finance, VI (4), 1993, 411-428.

[22] A.K. Nag, and A. Mitra, Exchange Rate of the Rupee and Purchasing Power Parity, Economic and Political Weakly, 33(25), 1998, 1525-1532.

[23] R. Kohli, Real Exchange Rate Stationarity in Managed Floats: Evidence from India, Economic and Political Weakly, 37(5), 2002, $475-477+479+482$.

[24] R.F. Engle, and C.W.J. Granger, Co-integration and error-correction: representation, estimation, and testing, Econometrica, 55, 25176.

[25] S. Johansen, and K. Juselius, Maximum Likelihood Estimation and Inference on Cointegration-with Application to the Demand for Money, Oxford Bulletin of Economics and Statistics, 5, 1990, 169-210.

[26] S. Johansen, Estimation and Hypothesis Testing of Cointegartion Vectors in Gaussian Vector Autoregressive Models, Econometrica, 59, 1991, 551-80.

[27] F. Diebold, and G. Redebusch, On the Power of Dickey-Fuller tests against fractional alternatives, Economics Letters, 35, 1991, 15560 .

[28] B. Chen, Long-run purchasing power parity: Evidence from some European Monetary System countries, Applied Economics, 27, 1995, 377-383.

[29] S. Johansen, Statistical Analysis of Cointegrating Vectors, Journal of Economic Dynamics and Control, 12, $1988,231-54$.

[30] G. Kouretas, The Canadian Dollar and Purchasing Power Parity during the Recent Float, Review of International Economics, 5, 1997, 467-477.

[31] Daubechies, Ten Lectures on Wavelets, SIAM, Philadelphia, 1992.

\section{Appendix}

Table 1: Time interpretation of different scales

\begin{tabular}{|c|c|c|}
\hline Scale & Monthly frequency & Period definition \\
\hline D1 & $2-4$ months & Short run \\
\hline D2 & $4-8$ months & \multirow{2}{*}{ Medium run } \\
\hline D3 & $8-16$ months & Long run \\
\hline D4 & $16-32$ months & \\
\hline A $_{4}$ & More than 32 months & \\
\hline
\end{tabular}

